\title{
Economic study for blend membrane production
}

\author{
A. El-Gendi ${ }^{*}$, H. Abdallah and A. Amin
}

\begin{abstract}
Background: In this work, an economic study for production reverse osmosis (RO) membrane from a blend of polyvinylchloride (PVC) with cellulose acetate (CA) was investigated. The model for predicting RO membrane performance was developed based on laboratory experimental data. The economic study was conducted to investigate the feasibility of producing blend RO polyvinylchloride/cellulose acetate (PVC/CA) membrane using a large-scale batch casting machine was developed and fabricated in workshop in the National Research Centre, Egypt.

Results: The cost of the prepared blend membrane using batch casting machine technique reached to $36 \$ / \mathrm{m}^{2}$ for flat sheet polymeric membrane which was cheaper than the cost of sheets of commercial $\mathrm{RO}$ membranes. The original capital investment will be recovered in 7.5 years with estimation of machine lifetime 25 years.

Conclusions: The economic study revealed that the establishing small factories to produce blend membranes using the fabricated machine is a promising and will create a reasonable profit.
\end{abstract}

Keywords: Mathematical model, RO desalination, Cost estimation, Casting machine, Membrane production

\section{Background}

Osmosis is a process by which a solvent flow through membrane from low concentration side to high concentration side (Rohlfs et al. 2016; El-Zanati et al. 2020). Assuming a pure solvent is flowing on one side of the membrane, the osmotic flow lasts when the chemical potentials of the solutions are equal on two sides of membrane. That will be occurred when a pressure excreted by a high concentration side, which must be high enough to discontinue solvent flow (Sobana and Panda 2011; Rohlfs et al. 2016; Ali et al. 2020). The reverse osmosis (RO) is a process by which pressure is applied to overcome the osmotic pressure on the high concentration side imposing solvent flow against the concentration gradient (Lee and Hsieh 2019; Jamal et al. 2004; El-Gendi et al. 2017).

RO models are quite important to predict the membrane performance under different operating conditions

*Correspondence: aymantaha2010@yahoo.com

Chemical Engineering and Pilot Plant Department, Engineering Research Division, National Research Centre, 33 El-Bohouth St. (Former El-Tahrir St.), P.O. Box 12622, Dokki, Giza, Egypt
(Wang et al. 2018; Achilli et al. 2014). Two types of models are used in literature, namely: the membrane transport model and lumped parameter model. The membrane transport model focuses on the membrane top layer, which mostly is thin skin of asymmetric membrane or composite membrane assuming that diffusion process occurs until the equilibrium state (Munubarthi et al. 2020; El-Gendi et al. 2017). Lumped parameter model is more suitable for control applications under steady state or transient conditions. Membrane transport model category can be subdivided into irreversible thermodynamics models, nonporous (homogenous membrane models), and pore models. The nonporous models adopt that ions transport occurs by diffusion through membrane structure, which is nonporous. The pore models assume that transport of ions occurs by convection along barrier layer of membrane (Mosqueda et al 2006; Subramani and Panda 2011).

Nonporous models category depends on the solutiondiffusion model. Solution-diffusion model assumes diffusion of both solvent and solute (Mansourpanah et al. 2011). This model can be used to inorganic and organic 
solutes. Solution-diffusion model is better applied for low water content membrane since it does not predict water flux accurately (Mazid 1984). Solution-diffusion model does not consider membrane layer imperfections or defects. In addition, negative solute rejection is not explained/considered by solution-diffusion model (Burghoff et al. 1980; Verhuelsdonk et al. 2010).

Sourirajan and Matsuura (1985) introduced the pore diffusion model to overcome the limitation experienced with the pore diffusion model. The model assumes a microporous membrane structure (capillary structure), which means that fluid transport through pores and surface phenomena are the main variables affecting separation mechanism of RO membrane. Pore diffusion model adopts the solvent transportation mechanism depending on the viscosity of the flow through uniform membrane pores. Solute transport is accomplished through the diffusion and the convection. The membrane barrier layer absorbs solvent and repels solute. Alexiadisa et al. (2007) found that the operating pressure plays an important role in pore diffusion model prediction accuracy. Due to membrane compaction at high pressure, the discrepancy between model and experimental results increases as the pressure increases (El-Gendi et al. 2012). By manipulating the factor $\mathrm{K}$ (membrane permeation coefficient), a better agreement between experimental results and model is observed despite the value of operating pressure.

Blending between polymers is applied to overcome some surface problems in the membrane production. Similarly, this method can improve the membrane performance by improving the properties of membrane such as hydrophilicity (Hidouri and Chaouachi 2020). RO asymmetric polyvinylchloride/cellulose (PVC/CA) membranes on woven and nonwoven supports were prepared in a previous work, which provided membranes with very good mechanical properties and hydrophilic nature with high performance (Abdallah et al. 2019). Blending polyvinylchloride with cellulose acetate also provided RO membrane can desalinate water with different grades of salinity (El-Gendi et al. 2017).

Membranes manufacturers are developing better technology and considering more applications to gradually decrease membrane costs (Nayar and Lienhard 2020; Kook et al. 2018; Loeb and Norman 1975). In the last 50 years, the membranes had extremely prohibitive prices per square meter. The drop in membrane cost is attributed to exponential growth membrane applications (Khaled et al. 2020; Kook et al. 2018; Loeb and Norman 1975). Nevertheless, there are still distinct membranes that command unaffordable cost, of US $\$ 1000 / \mathrm{m}^{2}$ or more. Such high prices are expected to fall due to better production technologies and increased applications. The market of membranes especially RO membranes are expected to reach a market size of US\$ 9.227 billion by the year 2022 (Researchandmarket 2020) as shown in Table 1.

Developing low-cost production units is very important to expand the membrane markets and applications. The economic study of membrane production will help to recognize the future needs of membrane industry.

The innovation of this current work is to discriminate if the produce homemade membranes are comparable with the industrial market membranes or not. For that challenge, the novelty of this work is production of blend membrane using the phase inversion method using manufactured homemade batch casting machine. Furthermore, in this work the blending process does not need any further treatment used for membrane surface. Like, interfacial polymerization of commercial membrane production for thin film composite $\mathrm{RO}$ membrane that needs excessive chemical treatment (Fang et al. 2013; Li et al. 2012) for the membrane surface which leading to increase the price of the produced membrane ( $\mathrm{Li}$ et al. 2014; El-Zanati and Abdallah 2014). In the present study the production process does not need interfacial polymerization process that makes the current process is cheaper than the most common process.

In this article, a mathematical model for predicting membrane performance has been developed. A cost study of prepared membrane was conducted and a comparison with commercial membrane was explored. The model and cost study were developed based on

Table 1 RO membranes module price in some companies at 2020-2021

\begin{tabular}{llll}
\hline RO modules & $\begin{array}{l}\text { Imported modules (\$) (excluding taxes } \\
\text { and customs) }\end{array}$ & Company & References \\
\hline 8040 Brackish Water RO Membrane & $330(\$)$ & Suez Water.Co (India) & Roestore (2020) \\
& $569.86(\$)$ & Membrania (Hydranautics Nitto & Membrania (2020) \\
& $255(\$)$ & Group) (USA) & Shanghai Geteng Water Treatment \\
Technology Co. (China) & Shgeteng (2020) \\
\hline
\end{tabular}


experimental data collected from our pervious and lab work (El-Gendi et al. 2017).

Based on raw materials cost, and production unit cost, a detailed mathematical model and cost study were developed.

\section{Methods}

\section{Desalination model assumptions and equations}

The model is developed based on solution-diffusion model considering solvent and solute mutual diffusion. The model is developed assuming the following five assumptions (Mazid 1984; El-Gendi et al. 2017):

- RO membrane has a dense structure with homogenous surface layer.

- Water dissolves and then diffuses through the surface layer.

- The solute (salt) diffusion and water diffusion are uncoupled due to the gradient of chemical potential across the membrane.

- Chemical potential gradient results from concentration gradient and difference of pressure across the membrane.

- Solution on both sides of the membranes is homogenous which means that the solute (salt) is evenly mixed (no active diffusion-taking place within a side).

The solvent diffusion can be calculated from Fick's law:

$$
J_{\mathrm{W}}=-D_{\mathrm{Wm}} \frac{\mathrm{dC}_{\mathrm{Wm}}}{\mathrm{dz}}
$$

where:

$J_{\mathrm{w}}$ : Permeate flux (solvent flux), $\mathrm{L} / \mathrm{m}^{2} \mathrm{~h}$,

$D_{\mathrm{Wm}}$ : The diffusivity of solvent (water diffusivity is $\left.3 \mathrm{E}-8 \mathrm{~m}^{2} / \mathrm{s}\right)$.

$C_{\mathrm{Wm}}$ : The solvent concentration within the membrane, which is a function of the chemical potential $\left(\mu_{\mathrm{W}}\right)$ of water. Osmotic pressure can be calculated from the following equation:

$$
\pi=\varnothing\left(\frac{n}{v}\right) R_{\mathrm{g}} T
$$

where:

$\varnothing$ : Osmotic pressure coefficient for sea water equal to

2,

$n$ : Dissolved solute number of moles,

$v$ : Mixer volume,

$R_{\mathrm{g}}$ : is the universal gas constant $(0.00831 \mathrm{~L} \mathrm{bar} / \mathrm{K} \mathrm{mol})$,

$T$ : temperature.
The rejection ratio can be calculated from the following equation:

$$
R=1-\frac{C_{\mathrm{P}}}{C_{\mathrm{f}}}
$$

where:

$R$ : The rejection ratio (\%).

$C_{\mathrm{P}}$ : Solute concentration of the permeate side.

$C_{\mathrm{f}}$ : Solute concentration of the feed side.

The solvent flux is calculated as following: -

$$
J_{\mathrm{W}}=A(\Delta P-\Delta \pi)
$$

The solute flux is calculated from the following equation:

$$
J_{\mathrm{s}}=B\left(C_{\mathrm{f}}-C_{\mathrm{P}}\right)
$$

where:

$J_{\mathrm{w}}$ and $J_{\mathrm{s}}$ : Solvent (water) and solute (salt) flux.

$A$ and $B$ are two parameters needed to fully characterize the system.

$\Delta P$ : The pressure difference across membrane.

Finally, water and solute fluxes throughout the membrane can be evaluated using the following equations, respectively:

$$
\begin{aligned}
& N_{\mathrm{w}}=J_{\mathrm{W}}+K_{1} * \Delta P \\
& N_{\mathrm{s}}=J_{\mathrm{s}}+K_{2} * \Delta P
\end{aligned}
$$

where: $N_{\mathrm{w}}$ and $N_{\mathrm{s}}$ are evaluated flux of water and salt, respectively. $K_{1}$ and $K_{2}$ are experimentally fitted parameters.

\section{Economic study}

A comparative cost study of prepared membranes using homemade batch casting machine was conducted. The total cost of prepared PVC/CA membrane was compared with commercially available membranes. The cost study started with conceptual design of batch membrane process production, then by considering raw materials, equipment cost, capital cost and working cost. The cost study was a nonbiased comparison according to the market conditions based on membrane performance, which was reviewed using the experimental data and the developed model.

\section{Results \\ Model verification}

The parameters affecting membrane preparation, such as polymer concentration, mixing time, solution temperature and effect of feeding pressure, were studied in a previous experimental work assumptions (El-Gendi et al. 
Table 2 Performance of prepared membrane at room temperature (feed Red Sea water sample 38528 ppm, 35 bar, $\mathrm{M}_{\text {CA3\% PVC16\%) }}$

\begin{tabular}{llll}
\hline Time (day) & Flux $\left(\mathbf{k g} / \mathbf{m}^{\mathbf{2}} \mathbf{~ h r}\right)$ & Rejection $(\%)$ & $\begin{array}{l}\text { Permeability } \\
\left(\mathbf{k g} / \mathbf{m}^{\mathbf{2}} \mathbf{~ h r} \text { bar }\right.\end{array}$ \\
\hline 1.0 & 32.55 & 99.90 & 0.93 \\
10 & 32.45 & 99.91 & 0.93 \\
14 & 32.39 & 99.92 & 0.93 \\
25 & 30.50 & 99.93 & 0.87 \\
36 & 28.60 & 99.95 & 0.82 \\
\hline
\end{tabular}

Where; CA: cellulose acetate, PVC: polyvinylchloride

Table 3 Estimated values of parameters in Eqs. (4)-(7)

\begin{tabular}{lll}
\hline $\begin{array}{l}\text { Parameters as listed in } \\
\text { Eqs. (4)-(7) }\end{array}$ & $\begin{array}{l}\text { Parameters in first-order } \\
\text { polynomial }\end{array}$ & Value \\
\hline A & A & -0.0015 \\
& B & 11.70952 \\
B & A & $-1.2 \mathrm{E}-10$ \\
& B & $2.34 \mathrm{E}-8$ \\
$K_{1}$ & A & -0.00343 \\
& B & 0.1737 \\
$K_{2}$ & A & $-6.1 \mathrm{E}-10$ \\
& B & $-2.4 \mathrm{E}-11$ \\
\hline
\end{tabular}

2017). Table 2 specifies the optimum results for membrane preparation, according to our previous experimental work.

The least square fitting method was used to estimate the unknown model parameters by fitting the experimental data to the developed model. After fitting the unknown parameters, a system of equations was developed. The developed equations were used to predict rejection ratio, water and salt fluxes, and permeability. The rejection percentage could be calculated using Eq. (8) as a function of time:

$$
R=(1 E-5) x+0.999
$$

where:

$X$ : The operating time in days.

Recalling Eqs. (4)-(7), unknown parameters were estimated as a function of time. Each parameter in Eqs. (4)(7) could be predicted using a first-order polynomial, as following:

$$
K=a x+b
$$

where $X$ is the operating time in days.

The values of such parameters are listed in following Table 3:

Figures 1, 2, and 3 show a comparison between the experimental data and model results for rejection

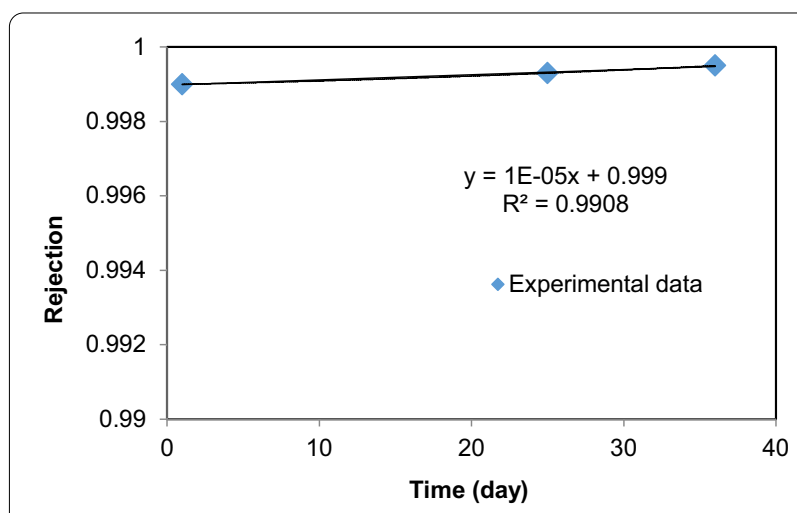

Fig. 1 Comparison between experimental data and model predicted rejection ratio

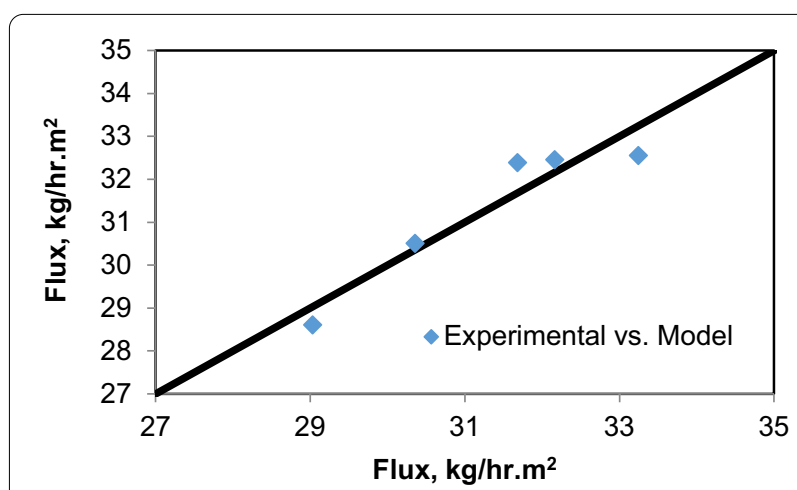

Fig. 2 Comparison between experimental data and model predicted water flux

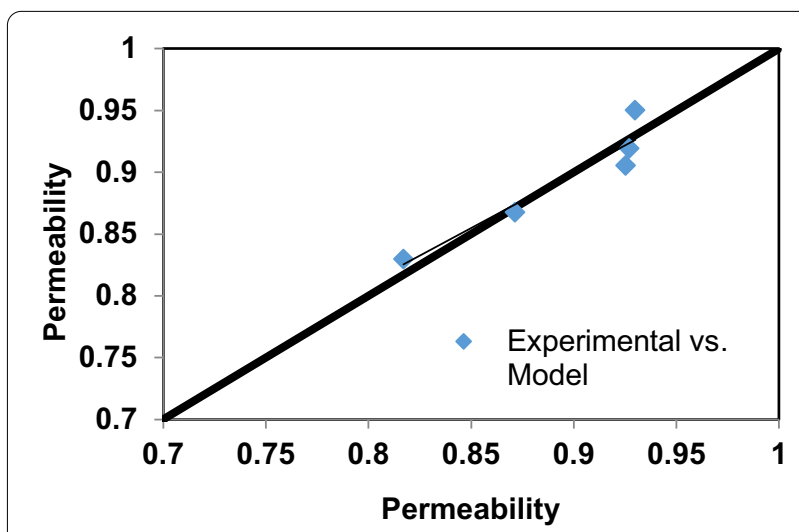

Fig. 3 Comparison between experimental data and model predicted permeability

percentage as a function of time, flux, and permeability, respectively. The comparison shows a good fit between experimental results and modeling results, which indicate that the model can be used to predict the performance 
of the membrane under different operating conditions. The experimental values of membrane performance indicators are rejection and relative permeability, at around 0.99 and $0.8-0.95$, respectively. The experimental results indicate that the membrane performance agrees well with the performance reported in the literature for the commonly used RO membranes in the market (Okamoto and Lienhard 2019; Pendergast and Hoek 2011; Cob et al. 2012). The developed membranes can compete well with the commercial RO membranes.

\section{Economic study}

The economic study includes systematic description of membrane preparation process. Starting from machine design, the economic study provides an estimation of the cost associated with each step according to technical knowledge, experimental data, model, and real marker prices. Through the economic study, all costs are evaluated in US dollar (\$).

\section{Conceptual design}

A design of casting machine to produce large flat sheet membrane is developed based on experimental results and the mathematical model. Two items were designed including batch casting machine and membrane solution preparation machine.
Figure 4 illustrates flow sheet of casting machine design, where the fabricated casting body is made of Perspex with supporting stainless steel legs. Four carriers of glass support are fixed on the machine body; carriers are able to move vertically in the coagulation bath. The machine is controlled with automatic control system to control casting knife and support carriers.

Figure 5 illustrates the solution preparation machine conceptual design, where the polymeric solution is prepared using mechanical stirrer with high rpm (up to $5000 \mathrm{rpm}$ ) using a mixer rode made of stainless steel. After preparation of polymeric solution, solution is drawn to the casting machine to form a membrane at thickness between 50 and $250 \mu \mathrm{m}$ according to production requirements. The membrane film is automatically casted and immersed into the coagulation bath to form membrane. Figure 6 indicates the fabricated batch-casting machine. The machine design is developed according to the following principles:

A production capacity of 32,640-membrane sheet/ year - sheet size $(65 \mathrm{~cm}$ width $\times 110 \mathrm{~cm}$ length).

The unit is in production mode for $340 \mathrm{~d} /$ year, $24 \mathrm{~h} /$ day for 3 shifts of $8 \mathrm{~h}$.

The production rate 4 membrane sheets/h
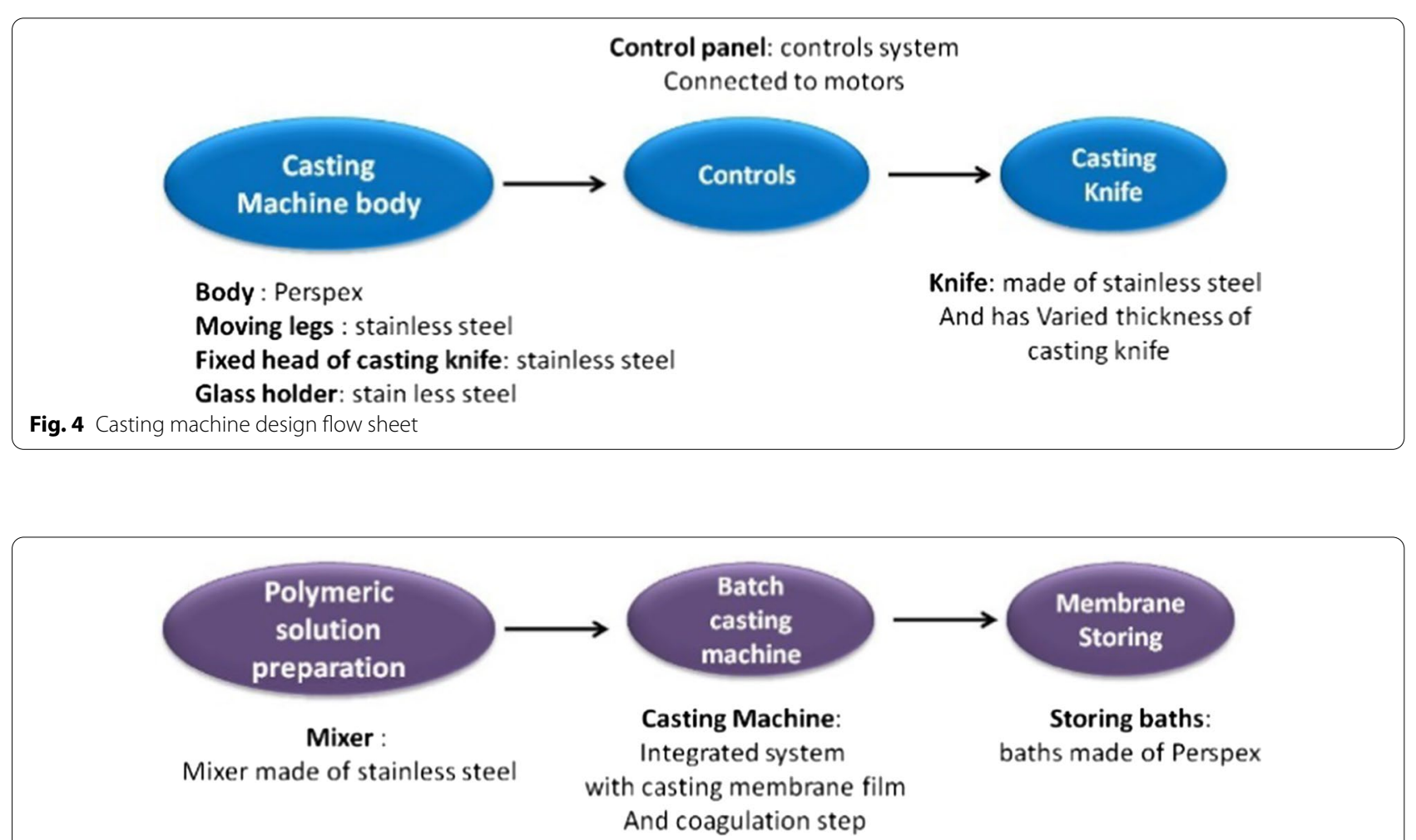

Fig. 5 Membrane production design flow sheet 


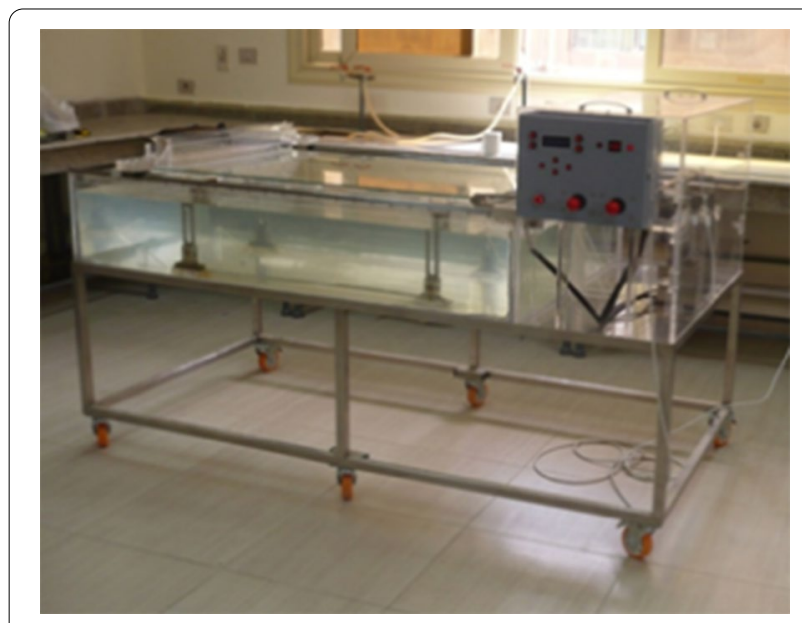

Fig. 6 Fabricated casting machine

The maintenance of casting machine will be carried out on monthly and yearly basis.

\section{Capital investments \\ Estimation of capital and processing cost}

\section{(a) Capital cost}

Table 4 illustrates the price of the individual items used to develop batch casting machine and membrane solution preparation machine. The price of mixer and vacuum pump is the actual market price. The casting machine and storing bath are manufactured and the tabled price represents the total cost including the raw materials and labor. In addition to machines price, several cost items should be considered to calculate the overall plant capital cost.

Table 5 illustrates a list of items considered for estimating the fixed capital investment required for the preliminary plant throughout the following cost analysis. All items are considered as a fraction of the two machines price (total value in Table 4, 8320 \$):
Table 5 Breakdown of fixed capital investment items for membrane production using batch casting machine

\begin{tabular}{ll}
\hline Item & Cost (\$) \\
\hline Purchased Equipment (PCE) & 8320 \\
Purchased Equipment Installation (10\%PCE) & 832 \\
Instrumentation And Controls (5\% PCE) & 416 \\
Electrical (10\% PCE) & 832 \\
Building Including Services (10\%PCE) & 832 \\
Yard Improvements (2.5\% PCE) & 208 \\
Service Facilities (10\% PCE) & 832 \\
Land (2.5\%PCE) & 208 \\
Total Direct Plant Cost (DPC) & 12,480 \\
Engineering and Supervision (5\%PCE) & 416 \\
Total Direct And Indirect Plant Cost & 12,896 \\
Contingency 5\% (DPC+ IDC) & 644.8 \\
Fixed Capital Investment (FCI) & $13,540.8$ \\
Working Capital Investment (10\% FCI) & 1354.08 \\
Total Capital Investment (FCI+WCI) & $14,894.88$ \\
\hline
\end{tabular}

- The installation cost is considered as $10 \%$ of the equipment price.

- The cost of instrumentation and control is considered as $5 \%$ of the equipment price.

- The electrical installation cost is estimated as $10 \%$ of the equipment price.

- Yard improvement cost for the manufacturing plant is considered as $2.5 \%$ of the equipment price.

- Water utilities are considered as 10 percentage of the equipment price.

- The costs of construction, engineering, and home office expenses are estimated as $5 \%$ of the equipment price.

- The cost for land and the accompanying surveys and fees is estimated as $2.5 \%$ of the equipment price.

- A contingency factor is included in the overall capital investment as 5\% of the direct and indirect plant costs (Max and Klaus 1991)

A working (overhead) capital investment is estimated as $10 \%$ of a fixed capital investment (Max and Klaus

Table 4 Cost of individual items used to develop designed machines

\begin{tabular}{|c|c|c|c|}
\hline Equipment type & Characteristic engineering parameters & Material of construction & Price (\$) \\
\hline High mechanical stirrer & $25 \mathrm{~L}$ & Stainless steel $316 \mathrm{~L}$ & 2500 \\
\hline Vacuum pump system & Power: $1 / 2 h p$ & Stainless steel $316 \mathrm{~L}$ & 320 \\
\hline Batch casting machine & $\begin{array}{l}\text { Rectangular shape composed of place for motors, cast- } \\
\text { ing knife and coagulation bath }\end{array}$ & $\begin{array}{l}\text { Body of machine is Perspex with Stain- } \\
\text { less steel } 316 \mathrm{~L} \text { frame }\end{array}$ & 5000 \\
\hline Bath for surface treatment and storing & $\begin{array}{l}\text { Rectangular shape and can carry glass plates that carry } \\
\text { formed membranes }\end{array}$ & $\begin{array}{l}\text { Body of bath is Perspex with stainless } \\
\text { steel } 316 \mathrm{~L} \text { frame }\end{array}$ & 500 \\
\hline Total Price (\$) & 8320 & & \\
\hline
\end{tabular}


1991). WCI is the total amount of money invested in the following items:

- The raw materials and supplies in stock.

- The final produced membrane as products in stock and the semifinal products in the process of being manufactured.

- An accounts receivable.

- The cash kept on hand for monthly payment of operating expenses such as salaries and raw materials purchase.

- An account payable.

- The taxes payable.

\section{(b) Processing Cost}

In addition to capital cost, processing (running) cost represents a major cost item. The processing cost includes labor, maintenance, and materials. According to Fig. 5, the plant has three sections. Table 6 presents the total monthly salaries for operating the three sections based on 312-membrane sheet/month. One of the major cost items in membrane production is the raw material cost.

Table 7 illustrates the raw material and the total production cost of PVC/CA blend membrane sheets per year. The total production cost is estimated assuming that the raw material costs are about $50-100 \%$ of the production cost/product unit, it assumed to be $75 \%$. According to the production cost from Table 7 , the PVC/CA membrane sheet cost is $32 \$$ /membrane sheet which mean 45 $\$ / \mathrm{m}^{2}$.

The estimation of total processing cost is shown in Table 8. The utilities are considered equal to the operating labor cost. Maintenance and repairs is considered 5\% of the equipment price (Table 4). Operating supplies is considered $15 \%$ of maintenance and repairs. The laboratory charges are considered $10 \%$ of the operating labor cost ( $\mathrm{Li}$ et al. 2012). Fixed charges include depreciation that is considered $10 \%$ of fixed capital investment (FCI),

Table 6 Monthly plant labor Costs (OPC) as the Egyptian worker salaries in government

\begin{tabular}{ll}
\hline Item & Cost, \$/month \\
\hline 1. Engineer (two Engineer) & 400 \\
2. Chemist (two chemist) & 300 \\
5. Skilled labor (three Labors) & 300 \\
6. Unskilled labor (two labors) & 100 \\
Total & 1100 \\
\hline
\end{tabular}

Table 7 Raw materials cost of blend (PVC/CA) membrane preparation per year

\begin{tabular}{llll}
\hline Raw material & Quantities & Prices & Cost, \$ \\
\hline PVC & $5440 \mathrm{~kg}$ & $15 \$ / \mathrm{kg}$ & 81,600 \\
CA & $2720 \mathrm{~kg}$ & $50 \$ / \mathrm{Kg}$ & 136,000 \\
Additives & $1088 \mathrm{~L}$ & $20 \$ / \mathrm{L}$ & 21,760 \\
Solvent & $27,200 \mathrm{lit}$ & $20 \$ / \mathrm{lit}$ & 544,000 \\
Requirements & & $85.02 \$$ & 783,360 \\
Raw cost for membrane preparation & & & 783,360 \\
$\begin{array}{l}\text { Estimated production cost (Raw } \\
\quad \text { material cost/0.75) }\end{array}$ & & $1,044,480$ \\
\hline
\end{tabular}

local taxes represent $2 \%$ of (FCI) and insurance, which represents $1 \%$ of (FCI).

Also, general expenses composed of administrative costs which is considered $20 \%$ of monthly plant labor costs (OPC), distribution and selling costs which is equal OPC and research and development costs which represents $2 \%$ of OPC. Manufacturing cost, general expenses, total product cost, total income, gross earnings, and net profit calculated using the following expressions:

Table 8 Estimation of total processing costs

\begin{tabular}{ll}
\hline Costs & Dollars (\$)/year \\
\hline Raw materials & 783,360 \\
Operating labor (OPC) & 13,200 \\
Utilities & 13,200 \\
Maintenance and repairs & 416 \\
Operating supplies & 62.4 \\
Laboratory charges & 1320 \\
Direct production costs & $811,558.4$ \\
Depreciation & 1354.08 \\
Local taxes & 270.816 \\
Insurance & 135.408 \\
Fixed charges & 1760.304 \\
Plant overhead costs 50\%OPC & 6600 \\
Manufacturing cost & $819,918.704$ \\
Administrative costs & 2640 \\
Distribution and selling costs & 13,200 \\
Research and development costs & 264 \\
General expenses & 16,104 \\
Total product cost (TPC) & $836,022.704$ \\
Total Income & $850,917.584$ \\
Gross earning cost & $14,894.88$ \\
Net Profit & $834,813.584$ \\
Annual cash flow & $18,050.35$ \\
Average annual profit & $16,696.27$ \\
\hline
\end{tabular}


Manufacturing cost $=$ fixed charges + direct production costs + plant overhead costs.

General expenses $=$ distribution and selling costs + administrative costs + research and development costs.

Total product cost $($ TPC $)=$ Manufacturing cost + Ggneral expenses.

Total income $=$ Total capital investment + TPC.

Gross earning cost $=$ Total income-TPC.

Net profit $=$ Total income - all expenses .

The annual cash flow and average annual profit can be calculated using the following expressions.

Annual cash flow $=(1-$ tax rate $) \quad(($ total income) - (all expenses) ) + depreciation.

Average annual profit $=$ Annual cash flow - annual depreciation cost.

After complete study the final total production cost / year was $836,022.704 \$$ year, accordingly the price of blend RO membrane sheet was $25.6 \$ /$ sheet that means $36 \$ / \mathrm{m}^{2}$.

\section{Payout Period $(\tau)$ :}

Payout period can be defined as the shortest length of time required to get back the original capital investment in the form of the cash flow to the project. The calculation of payout period indicates that the original capital investment will be recovered in 7.5 years. Assuming 25 years as the service life of machines, the payout period can be calculated from Eq. (10) (Max and Klaus 1991):

$$
\tau=\mathrm{FCI} /(X / Y)
$$

where:

FCI: is the fixed capital investment, \$

$x$ : is an average profit per year, $\$$

$y:$ is an average depreciation per year, $\$$

$\tau=7.5$ years.

\section{Cost comparison with commercial RO flat sheet membranes}

The price of commercial RO flat sheet membrane is in the ranges between $102.58 \$ / \mathrm{m}^{2}$ and $238.91 \$ / \mathrm{m}^{2}$ (Sterlitech 2020) in comparison with the developed PVC/ CA membrane which cost $36 \$ / \mathrm{m}^{2}$. Thus, the developed membrane demonstrates substantial economic edge over commercial membranes. These results prove that the produced blende membranes $\mathrm{PVC} / \mathrm{CA}$ are more economically than the commercial membranes, which require many steps composed of drawing, washing, and then interfacial polymerization that requires primary treatment units, using dangerous chemicals such as meta-phenylene diamine and using a unit or basin for hexane an organic chloride compound such as trimesoyl chloride, which is followed by a heat treatment step which needs dryer, and all these many steps require equipment in millions, which overburden the small investors. In industrial scale, flat sheet used in membrane bioreactors (MBR) fabrication modules are used in wastewater treatment, while $\mathrm{RO}$ membranes modules mostly are spiral wound modules, where the flat sheet membranes are rolled using feed spacers and permeate carrier to fabricate RO spiral wound module. The prepared membranes PVC/CA can be used in spiral wound module fabrication. The merits of our batch machine are eliminating the excessive treatment of the membrane surface by interfacial polymerization because the blend membrane using PVC and CA exhibited good RO membrane performance and can make a competitive with TFC RO (El-Gendi et al. 2017; Abdallah et al. 2019).

\section{Discussion}

This work may serve the owners of small projects who have limited capabilities, and therefore, productivity of the membranes does not require huge machines for the production of membranes, but it is sufficient to produce flat sheet membranes with the system used in this article especially, the price of the produced membrane which is lower than the importer or the sheets that produced globally. This may be due to the taxes and customs that may be imposed on the imported product. Therefore, the manufacturing cost of the spiral wound module using this kind of membrane can reduce the price approximately to a third of the imported module price, especially if the manufacturers use the raw materials from local market.

\section{Conclusion}

Mathematical model shows a good fit between experimental results and mathematical model results, which indicate that the model can be used to predict the performance of the membrane under different operating conditions. An economic study was conducted to investigate the production of a flat sheet membrane using homemade batch casting machine fabricated in National Research Centre, Egypt. The economic study indicated that the price of produced flat sheet membrane was 36 $\$ / \mathrm{m}^{2}$. The developed membrane provides a cheaper and economical substitute than the commercial membranes. The present study illustrated that the establishment of small factory using developed machines will have a payout period of 7.5 year with the average annual profit $16,696.27$ \$. The developed membrane can be used to develop spiral wound modules by employing local Egyptian resources, where the calculation showed that the 
developed spiral wound module can be produced at a competitive price compared to the commercial spiral wound modules.

\section{List of symbols}

RO: Reverse osmosis; PVC: Polyvinylchloride; J $J_{w}$ : Permeate flux (solvent flux), L/ $\mathrm{m}^{2} \mathrm{~h} ; D_{\mathrm{Wm}}$ : The diffusivity of solvent (water diffusivity is $\left.3 \mathrm{E}-8 \mathrm{~m}^{2} / \mathrm{s}\right) ; C_{\mathrm{Wm}}$ :The solvent concentration within the membrane; $A$ : Cellulose acetate; $\varnothing$ : Osmotic pressure coefficient for sea water equal to $2 ; \boldsymbol{n}$ : Dissolved solute number of moles; $v$ : Mixer volume; $R_{\mathrm{g}}$ : Universal gas constant ( $\left.0.00831 \mathrm{~L} \mathrm{bar} / \mathrm{K} \mathrm{mol}\right)$; T: Temperature; $R$ : The rejection ratio (\%); $C_{\mathrm{P}}$ : Solute concentration of the permeate side; $C_{f}$ : Solute concentration of the feed side; $J_{w}$ : Solvent (water) flux; J: Solute (salt) flux; $\triangle P$ : The pressure difference across membrane.

\section{Acknowledgements}

Not applicable.

\section{Authors' contributions}

A.E. is the main author, he had proposed the subject and Pursued to provide a financial support for this research, and he is responsible for planning and implementation of this research and was a major contributor in writing the manuscript. H.A. did the experimental part of membranes preparation and responsible for the determination of the polymer blends. A.M.A. is responsible for the model and discussion of its results. All authors read and approved the final manuscript.

\section{Funding}

Not applicable.

\section{Availability of data and material}

All data generated or analyzed during this study are included in this published article.

\section{Declarations}

Ethics approval and consent to participate Not applicable.

\section{Consent for publication}

Not applicable.

\section{Competing interests}

The authors declare that they have no competing interests.

Received: 18 June 2021 Accepted: 7 July 2021

Published online: 14 July 2021

\section{References}

Abdallah H, Shalaby MS, El-Gendi A, Shaban A, Zhu BK (2019) Effectiveness of a coagulation step and polyester support on blend polyvinylchloride membrane formation and performance. J Polym Eng 3:351-359

Achilli A, Prante JL, Hancock NT, Maxwell EB, Childress AE (2014) Experimental results from RO-PRO: a next generation system for low-energy desalination. Environ Sci Technol 48:6437-6443

Alexiadisa A, Wiley DE, Vishnoi A, Leea RHK, Fletcher DF, Bao J (2007) CFD modelling of reverse osmosis membrane flow and validation with experimental results. Desalination 217(1-3):242-250

Ali W, Pathak N, Shon H, Hilal N (2020) Forward osmosis membranes and processes: a comprehensive review of research trends and future outlook. Desalination. https://doi.org/10.1016/j.desal.2020.114455

Burghoff HG, Lee K, Pusch W (1980) Characterization of transport across cellulose acetate membranes in the presence of strong solute membrane interactions. J Appl Polym Sci 25(3):323-347

Cob SS, Beaupin C, Hofs B, Nederlof MM, Harmsen DJ, Cornelissen ER, Zwijnenburg A, Güner FG, Witkamp GJ (2012) Silica and silicate precipitation as limiting factors in high-recovery reverse osmosis operations. J Membr Sci 423-424:1-10. https://doi.org/10.1016/j.memsci.2012.07.016

EL-Gendi A, Ali SS, Ahmed SA, Talaat HA (2012) Development of membrane blend using casting technique for water desalination. Membrane Water Treat 3(2):185-200

El-Gendi A, Abdallah H, Amin A, Amin ShK (2017) Investigation of polyvinylchloride and cellulose acetate blend membranes for desalination. J Mol Struct 1146:14-22

El-Zanati E, Abdallah H (2014) Inter-facially synthesized thin film composite nanofiltration flat sheet membrane by flow through process. Eur J Sci Res 127:284-297

El-Zanati EM, Farg E, Taha E, El-Gendi A, Abdallah H (2020) Preparation and characterization of different geometrical shapes of multi-bore hollow fiber membranes and application in vacuum membrane distillation. J Anal Sci Technol 11(47):1-16

Fang W, Shi L, Wang R (2013) Interracially polymerized composite nanofiltration hollow fiber membranes for low-pressure water softening. J Membr Sci 430:129-139

Hidouri AK, Chaouachi B (2020) Manufacture of hydrophobic membranes using recycled polymers for the brackish water distillation. In: The 11th international renewable energy congress

Jamal K, Khan MA, Kamil M (2004) Mathematical modeling of reverse osmosis systems. Desalination 160:29-42

Khaled F, Hidouri K, Criscuoli A, Chouachi B (2020) Supply of solar energy in vacuum membrane. Distill Ambient Int J Ambient Energy Hamzaoui. https://doi.org/10.1080/01430750.2020.1789738

Kook S, Lee C, Nguyen TT, Lee J, Shon HK, Kim IS (2018) Serially connected forward osmosis membrane elements of pressure-assisted forward osmosisreverse osmosis hybrid system: process performance and economic analysis. Desalination 448:1-12

Lee D-J, Hsieh M-H (2019) Forward osmosis membrane processes for wastewater bioremediation: research needs. Biores Technol 290:121795. https:// doi.org/10.1016/j.biortech.2019.121795

Li X, Wang KY, Helmer B, Chung TS (2012) Thin-film composite membranes and formation mechanism of thin-film coats on hydrophilic cellulose acetate propionate substrates for forward osmosis processes. Ind Eng Chem Res 51:10039-10050

Li Y, Su Y, Dong Y, Zhao X, Jiang Z, Zhang R, Zhao J (2014) Separation performance of thin-film composite nanofiltration membrane through interfacial polymerization using different amine monomers. Desalination 333:59-65

Loeb S, Norman RS (1975) Osmotic power plants. Science 189:654-655 Mansourpanah Y, Madaeni SS, Rahimpour A, Adeli M, Hashemi MY, Moradian MR (2011) Fabrication new PES-based mixed matrix nanocomposite membranes using polycaprolactone modified carbon nanotubes as the additive: property changes and morphological studies. Desalination 277:171-177

Max SP, Klaus D (1991) Timmerhaus. In: Plant design and economic for chemical engineering, 4th edn. McGraw-Hill Chemical Engineering Series. ISBN 0-97-100871-3

Mazid MA (1984) Mechanisms of transport through reverse osmosis membranes. Sep Sci Technol 19(6-7):357-373

Membrania (2020) espa-energy-saving-polyamide, https://www.membrania. eu/category/hydranauticsmembranes/subCategory/reverse-osmosis-ro/ type/ /product/hydranautics-espa4-ld-8040

Mosqueda DB, Narbaitz RM, Matsuura T (2006) Effects of preparation conditions on the surface modification and performance of polyethersulfone ultrafiltration membranes. J Appl Polym Sci 99:2978-2988

Munubarthi KK, Gautam DK, Reddy KA, Subbiah S (2020) Distributed parameter system modeling approach for the characterization of a high flux hollow fiber forward osmosis (HFFO) membrane. Desalination 496:114706

Nayar KG, Lienhard JH (2020) Brackish water desalination for greenhouse agriculture: comparing the costs of RO, CCRO, EDR, and monovalentselective EDR. Desalination 475:114-188

Okamoto Y, Lienhard J (2019) How RO membrane permeability and other performance factors affect process cost and energy use: a review. Desalination. https://doi.org/10.1016/j.desal.2019.07.004

Pendergast MT, Hoek E (2011) A review of water treatment membrane nanotechnologies. Energy Environ Sci 4:1946-1971. https://doi.org/10.1039/ COEE00541J 
Researchandmarkets (2020) global-reverse-osmosis-ro-systemsmarket,.https://www.researchandmarkets.com/reports/4396337/g Roestore (2020) ro-membrane-ge-8040-ag. https://roestore.com/product Rohlfs W, Thiel GP, Lienhard JH (2016) Modeling reverse osmosis element design using superposition and an analogy to convective heat transfer. J Membr Sci 512:38-49

Shgeteng (2020) China-Water-Treatment-Industrial-8040-Reverse-OsmosisRO-Membrane-Price. https://shgeteng.en.made-inchina.com/product/ IscEuAgHgjkU/.html

Sobana S, Panda R (2011) Review on modelling and control of desalination system using reverse osmosis. Rev Environ Sci Bio/technol 10(2):139-150

Sourirajan S, Matsuura T (1985) Reverse osmosis/ultrafiltration process principles. National Research Council Canada, Ottawa

Sterlitech (2020) reverse osmosis-ro-membrane. https://www.sterlitech.com/
Subramani S, Panda R (2011) Review on modelling and control of desalination system using reverse osmosis. Rev Environ Sci Bio/technol 10:139-150. https://doi.org/10.1007/s11157-011-9233-z

Verhuelsdonk M, Attenborough T, Lex O, Altmann T (2010) Design and optimization of seawater reverse osmosis desalination plants using special simulation software. Desalination 250:729-733

Wang S, Zhu Q, Zhang C, He B, Chen Q, Pan M (2018) Model-based optimization and comparative analysis of open-loop and closed-loop RO-PRO desalination systems. Desalination 446:83-93

\section{Publisher's Note}

Springer Nature remains neutral with regard to jurisdictional claims in published maps and institutional affiliations.

\section{Submit your manuscript to a SpringerOpen ${ }^{\circ}$ journal and benefit from:}

- Convenient online submission

- Rigorous peer review

- Open access: articles freely available online

- High visibility within the field

- Retaining the copyright to your article

Submit your next manuscript at $\gg$ springeropen.com 